\title{
Inductive Ability of Human Developing and Differentiated Dental Mesenchyme
}

\author{
Liwei Zheng ${ }^{\mathrm{a}, \mathrm{b}}$ Rungnapa Warotayanont ${ }^{\mathrm{a}}$ Jonathan Stahl ${ }^{\mathrm{a}}$ Ryo Kunimatsu ${ }^{\mathrm{a}}$ \\ Ophir Klein $^{\mathrm{a}}$ Pamela K. DenBesten ${ }^{\mathrm{a}}$ Yan Zhang ${ }^{\mathrm{a}}$ \\ ${ }^{a}$ Department of Orofacial Sciences, University of California, San Francisco, Calif., USA; ${ }^{b}$ State Key Laboratory of \\ Oral Diseases, Sichuan University, Chengdu, China
}

\section{Key Words}

Ameloblasts · Amelogenin - Dental mesenchymal cells .

Human embryonic stem cells · Odontogenic competence .

Reprogramming $\cdot$ Transcription factors

\begin{abstract}
The development of cell-based therapeutic strategies to bioengineer tooth tissue is a promising approach for the treatment of lost or damaged tooth tissue. The lack of a readily available cell source for human dental epithelial cells (ECs) severely constrains the progress of tooth bioengineering. Previous studies in model organisms have demonstrated that developing dental mesenchyme can instruct nondental epithelium to differentiate into enamel-forming epithelium. In this study, we characterized the ability of fetal and adult human dental mesenchyme to promote differentiation of human embryonic stem cell (hESC)-derived ECs (ES-ECs) into ameloblast-lineage cells. ES-ECs were co-cultured either with human fetal dental mesenchymal cells (FDMCs) or with adult dental mesenchymal cells (ADMCs) in either a three-dimensional culture system, or in the renal capsules of SCID mice. When co-cultured with FDMCs in vitro, ES-ECs polarized and expressed amelogenin. Tooth organ-like structures assembled with epithelium and encased mesenchyme and
\end{abstract}

developing enamel-like structures could be detected in the complexes resulting from in vitro and ex vivo co-culture of ES-ECs and FDMCs. In contrast, co-cultured ES-ECs and ADMCs formed amorphous spherical structures and occasionally formed hair. Transcription factors were significantly upregulated in FDMCs compared to ADMCs including MSX1, GLI1, LHX6, LHX8, LEF1 and TBX1. In summary, FDMCs but not ADMCs had the capacity to induce differentiation of ES-ECs into ameloblast lineage cells. Further characterization of the functional differences between these two types of dental mesenchyme could enable reprogramming of ADMCs to enhance their odontogenic inductive competence.

(c) 2013 S. Karger AG, Basel

\section{Introduction}

Ameloblasts, highly specialized enamel-forming dental epithelial cells (ECs), go through multiple stages of differentiation during tooth development. As ameloblasts differentiate from the presecretory stage to the secretory stage, enamel matrix proteins consisting primarily of amelogenins are synthesized and secreted. Amelogenins are alternatively spliced matrix proteins required for nucleation and growth of enamel hydroxyapatite crys-

\section{KARGER}

E-Mail karger@karger.com www.karger.com/cto
(C) 2013 S. Karger AG, Basel

$1422-6405 / 13 / 1982-0099 \$ 38.00 / 0$
Dr. Yan Zhang

Department of Orofacial Sciences

University of California, 513 Parnassus Avenue

San Francisco, CA 94143-0422 (USA)

E-Mail yan.zhang2@ucsf.edu 


\begin{tabular}{ll}
\hline Abbreviations used in this paper \\
\hline ADMCs & $\begin{array}{l}\text { adult dental mesenchymal cells (derived from human } \\
\text { permanent teeth) }\end{array}$ \\
BMP & $\begin{array}{l}\text { bone morphogenetic protein } \\
\text { cytokeratin }\end{array}$ \\
CK & dental mesenchymal cell \\
DMC & Dulbecco's modified Eagle's medium \\
DMEM & epithelial cell \\
EC & human embryonic stem cell-derived epithelial cells \\
ES-ECs & Ham's F12 \\
F12 & fibroblast growth factor \\
FGF & fetal dental mesenchymal cells (derived from human \\
FDMCs & developing tooth organs) \\
hESCs & human embryonic stem cells \\
KGM2 & keratinocyte growth medium 2 \\
LEF1 & lymphoid enhancer-binding factor 1 \\
LHX & LIM/homeobox protein \\
$M S X 1$ & Msh homeobox 1 \\
qPCR & quantitative polymerase chain reaction \\
SHH & sonic hedgehog homolog \\
TBX1 & T-box 1 \\
VitC & vitamin C \\
\hline
\end{tabular}

tals during amelogenesis [Fincham et al., 1994; Moradian-Oldak et al., 1998; Beniash et al., 2005]. In the maturation stage, these proteins are subsequently removed, and mineralization is completed. This process leads to the formation of tooth enamel, which is the hardest tissue in the human body, providing protection, strength and wear resistance to the teeth.

Tooth tissue formation is guided by reciprocal signaling interactions between the ectodermally derived dental epithelium and cranial neural crest-derived dental mesenchyme [Thesleff and Hurmerinta, 1981; Ruch et al., 1983; Thesleff et al., 1995a; Thesleff and Sharpe, 1997; Thesleff and Mikkola, 2002]. The first sign of tooth tissue formation is the localized thickening of oral ECs lining the first branchial arch in the location where teeth will form. The presumptive dental ECs form an epithelial band (so-called dental placode) and invaginate into the underlying mesenchyme. In mice, ECs from the dental placode can instruct tooth formation ex vivo when recombined with either dental mesenchyme or nondental mesenchyme [Cummings et al., 1981; Mina and Kollar, 1987; Thesleff et al., 1995a].

In response to the epithelially derived signals, which include bone morphogenetic protein (BMP) 4 and fibroblast growth factor (FGF)8 [Thomas et al., 1997; Bei and Maas, 1998; Hardcastle et al., 1998], the underlying mesenchymal cells proliferate and condense around the thickened epithelium to form a bud-like structure. Reciprocally, the dental mesenchyme secretes BMP4, WNT5a, FGF3 and other signaling molecules to instruct the dental epithelium to form a cap-like enamel organ, where polarized and columnar inner enamel ECs appear [Cai et al., 2011]. In the following bell stage of tooth development, inner enamel ECs further elongate to differentiate into pre-ameloblasts, and the adjacent layer of dental mesenchyme differentiates into odontoblasts. After odontoblasts start to deposit dentin matrix, presecretory ameloblasts progress to secretory ameloblasts, then to transition and maturation ameloblasts. In the fully formed teeth, dental mesenchyme forms dentin, odontoblasts and vital pulp tissue, in which mesenchymal stem cells still remain [Gronthos et al., 2000, 2002]. Secretory ameloblasts produce stage-specific enamel matrix proteins, including amelogenin, ameloblastin and enamelin [Robinson et al., 1998], to modulate enamel crystal formation. Maturation ameloblasts finalize the mineralization process by removing matrix proteins and depositing minerals.

Evidence from developmental biology studies indicates that cell-based tooth tissue bioengineering will require both a viable source of epithelial cells and a source of dental mesenchyme to reconstitute the cascade of reciprocal signaling interactions that can lead to tooth formation. Mesenchymal stem cells, available from dental pulp of human exfoliated deciduous teeth and extracted adult molars, as well as from root apical dental papilla, are capable of regenerating dentin and pulp complex [Gronthos et al., 2000, 2002; Miura et al., 2003; Sonoyama et al., 2008; Estrela et al., 2011]. In humans, enamel loses the capacity to regenerate itself since enamel-forming ameloblasts are lost once the teeth erupt into the oral cavity [Vaahtokari et al., 1996]. Therefore, the lack of readily available human dental ECs severely constrains the advance of enamel tissue and whole tooth bioengineering.

Human embryonic stem cells (hESCs) have been considered as a potential source of ECs for skin tissue regeneration [Green et al., 2003; Clark et al., 2004; Metallo et al., 2008]. We have shown that epithelial cells differentiated from hESCs express FGF8, MSX 1 and cytokeratins (CKs) similar to those found in human ameloblast lineage cells [Zheng et al., 2013]. In this study, we determined the ability of human dental mesenchyme derived from developing fetal primary tooth organs and adult dental mesenchyme (including adult dental pulp stem cells) to differentiate hESC-derived ECs (ES-ECs) into ameloblast lineage cells. 


\section{Materials and Methods}

\section{Induction of hESCs}

The hESC line WA09 (WiCell Research Institute, Madison, Wisc., USA) was cultured and maintained on a layer of mitotically inactivated mouse embryonic fibroblast cells in Dulbecco's modified Eagle's medium/Ham's F12 (DMEM/F12) containing 20\% knockout serum replacement (Invitrogen, Carlsbad, Calif., USA), 1x MEM nonessential amino acids (Sigma-Aldrich, St. Louis, Mo., USA), $1 \mathrm{mM}$ L-glutamine, $0.1 \mathrm{mM} \beta$-mercaptoethanol, $4 \mathrm{ng} / \mathrm{ml}$ basic FGF (Invitrogen), and $50 \mathrm{mg} / \mathrm{ml}$ penicillin and streptomycin [Klimanskaya et al., 2004]. All procedures using the hESCs followed the guidelines set by the Human Gamete, Embryo and Stem Cell Research Comittee at USCF. Prior to induction, hESCs were passaged twice on Matrigel ${ }^{\mathrm{TM}}$ (BD Biosciences, San Jose, Calif., USA)-coated dishes to eliminate contamination of mouse embryonic fibroblast cells. For epithelial induction, hESCs were cultured in DMEM/F12 supplemented with $1 \mu \mathrm{M}$ retinoid acid (SigmaAldrich) and $12.5 \mathrm{ng} / \mathrm{ml} \mathrm{BMP} 4$ (Invitrogen) for 7 days. The medium was changed daily. Cell morphology was monitored under an inverted phase-contrast microscope. Expression of the EC marker, CK14, was analyzed by quantitative polymerase chain reaction (qPCR) using total RNA purified from induced hESCs.

Upon achieving an epithelial phenotype identified by cobblestone cell morphology and increased CK14 expression, several culture conditions were used to explore the possibility that enamel matrix proteins and Wnt signaling could induce further differentiation of ES-ECs toward an ameloblast lineage. ES-ECs were cultured for 3 days in either keratinocyte growth medium 2 (KGM2; Lonza Inc., Walkersville, Md., USA), KGM2 supplemented with $100 \mu \mathrm{M} \mathrm{LiCl}$ (Sigma-Aldrich), KGM2 supplemented with $1 \mu \mathrm{g} / \mathrm{ml}$ purified recombinant human amelotin protein, KGM2 supplemented with 1 $\mu \mathrm{g} / \mathrm{ml}$ purified recombinant human amelogenin protein, or human fetal ameloblast lineage cell conditioned medium.

\section{Co-culture of ES-ECs with Dental Mesenchymal Cells}

All human tissues were collected under regulations and guidelines set by the University of California San Francisco Committee on Human Research. Human tooth organs were dissected from 16- to 18-week-old fetal cadavers. Tooth organs were digested with Dispase II (Roche Applied Science, Indianapolis, Ind., USA) for 15 min at $37^{\circ} \mathrm{C}$. Dental epithelia were then separated from dental mesenchyme using fine point forceps under a dissecting microscope (SMZ1000; Nikon). Epithelial and mesenchymal tissues were digested with $2 \mathrm{mg} / \mathrm{ml}$ collagenase/Dispase II (Roche Applied Science) at $37^{\circ} \mathrm{C}$ for $2 \mathrm{~h}$, followed by digestion with $0.05 \%$ trypsin/ EDTA for $5 \mathrm{~min}$ at $37^{\circ} \mathrm{C}$. KGM2 supplemented with $0.05 \mathrm{mM}$ calcium was used to grow ameloblast lineage cells as described previously [Yan et al., 2006]. The medium was collected daily to be used as human fetal ameloblast lineage cell conditioned medium to induce the differentiation of ES-ECs as mentioned above.

Human fetal dental mesenchymal cells (FDMCs) isolated from developing primary tooth organs were grown in DMEM supplemented with $15 \%$ fetal bovine serum, $50 \mathrm{mg} / \mathrm{ml}$ penicillin and streptomycin. Cells isolated from pulp tissue of extracted human third molars (adult dental mesenchymal cells, ADMCs) were cultured in DMEM as described previously [Gronthos et al., 2000; Miura et al., 2003].

Cultured FDMCs or ADMCs were harvested at 90\% confluence. ES-ECs were harvested 7 days after induction. ES-ECs and either FDMCs or ADMCs were then co-cultured in a 3D Matrigel drop system to facilitate cell compartmentalization for multicellular assembly and reciprocal signaling crosstalk. In this system, one million FDMCs or ADMCs were resuspended in $25 \mu \mathrm{l}$ DMEM, and then mixed with $25 \mu \mathrm{l}$ ice-chilled Matrigel (BD Biosciences). The cell/Matrigel complex was dropped onto a Transwell membrane (BD Biosciences). One million ES-ECs were then resuspended in $25 \mu \mathrm{KGM} 2$ and mixed with $25 \mu \mathrm{l}$ ice-chilled Matrigel. The EC-Matrigel complex was laid on the top of either FDMC or ADMC Matrigel drop. KGM2 was added to the upper chamber of Transwell to culture ECs, and DMEM supplemented with 10\% FBS was added to the lower chamber of Transwell (fig. 1a). Co-cultures were maintained at $37^{\circ} \mathrm{C}$ in $5 \%$ carbon dioxide. One week later, KGM2 was supplemented with $1 \mathrm{mM}$ calcium, and DMEM was supplemented with $10 \mathrm{nM}$ dexamethasone, $50 \mu \mathrm{g} / \mathrm{ml}$ ascorbic acid, $10 \mathrm{~mm} \beta$-glycerophosphate and $2 \mathrm{~mm}$ L-glutamine. ES-ECs, ADMCs or FDMCs alone were cultured in Matrigel to serve as controls. Cell/Matrigel complexes were maintained in these supplemented media for 8 weeks.

After rinsing with cold PBS, cell/Matrigel complexes were harvested, embedded in OCT, and cryosectioned for histological analysis. For gene expression analysis, cells were recovered from Matrigel using cell recovery solution (BD Biosciences) according to the manufacturer's instruction.

Gene Expression Analysis by $q P C R$

Total RNA was purified from the cells recovered from Matrigel using the RNeasy plus micro kit (Qiagen, Valencia, Calif., USA). A cDNA library was generated from $0.1 \mu \mathrm{g}$ of total RNA using the SuperScript ${ }^{\mathrm{TM}}$ III first-strand synthesis system (Invitrogen). Expression of target genes was characterized by qPCR using the ABI 7500 system (Applied Biosystems, Carlsbad, Calif., USA). Primers and probes used to detect endogenous control 18S, and target genes were also purchased from Applied Biosystems. Relative expression levels of target genes were measured by the $\Delta \Delta \mathrm{Ct}$ method as previously published [Thomsen et al., 2010]. Data were analyzed using one-way ANOVA followed by Tukey's post hoc test; $\mathrm{p}<0.05$ was considered significant.

\section{Histological and Immunohistochemical Studies}

Cell/Matrigel complexes were washed with PBS, incubated in $20 \%$ sucrose at $37^{\circ} \mathrm{C}$ for $6 \mathrm{~h}$, embedded in OCT compound and then cryosectioned. The sections were either stained with hematoxylin and eosin, or immunostained for amelogenin protein.

Amelogenin immunostaining was performed by first blocking the sections with $3 \%$ goat serum, $0.1 \%$ BSA and $0.1 \%$ Triton for $1 \mathrm{~h}$ at room temperature. The sections were then incubated overnight at $4^{\circ} \mathrm{C}$ with polyclonal rabbit anti-recombinant human amelogenin IgG, as previously described [Zhang et al., 2006]. The sections were then thoroughly washed with PBS and incubated with FITC-conjugated anti-rabbit secondary antibody (Sigma-Aldrich) for $1 \mathrm{~h}$. Cell nuclei were counterstained with $0.5 \mu \mathrm{g} / \mathrm{ml}$ Hoechst 33342 (Invitrogen) for $5 \mathrm{~min}$. After mounting, the sections were photographed under a Nikon Eclipse 300 fluorescence microscope (Compix Inc., Sewickley, Pa., USA).

\section{Renal Capsule Transplantation}

Nine-week-old SCID CD-1 male mice (Charles River, Wilmington, Mass., USA) were housed in the animal barrier facility of the University of California, San Francisco, Calif., USA, in accor- 
dance with the guideline approved by UCSF Laboratory Animal Resource Center.

ES-ECs and either FDMCs or ADMCs were co-cultured in Matrigel as described above, then maintained for 3 days in vitro prior to transplantation. ADMCs, FDMCs or ES-ECs cultured in Matrigel were included as controls. ADMCs/ES-ECs, FDMCs/ESECs and control cells, all in Matrigel, were then transplanted into renal capsules of SCID mice. Each renal capsule maintained 2 transplants. Transplants were recovered 8 weeks after transplantation, dehydrated in $20 \%$ sucrose overnight and fixed in $4 \%$ buffered paraformaldehyde, and then processed for hematoxylin and eosin staining and immunostaining.

\section{Comparative Gene Expression Analysis of Human FDMCs} and $A D M C s$

Total RNA was purified from first-passage human FDMCs and ADMCs using a Qiagen RNeasy mini kit, and cDNA was generated using the SuperScript III first-strand synthesis system (Invitrogen). Conventional PCR was used to amplify transcription factors, including MSX (Msh homeobox) 1, MSX2, DLX1, DLX2, DLX5, GLI1, GLI2, GLI3, LHX (LIM/homeobox protein) 6, LHX8, LEF1 (lymphoid enhancer-binding factor 1), RUNX2, PAX9, PRX1, PRX2 and TBX1 (T-box 1; see table 1 for primer sequences). After PCR amplification, an equal volume of each PCR product was separated on agarose gel by electrophoresis. The intensities of DNA bands were measured using NIH ImageJ (version 1.46) software. The expression level of each gene was normalized to GAPDH serving as an endogenous control. Student's t test was performed to compare the relative expression level of each target gene in FDMCs and ADPCs.

Characterization of the Odontogenic Inductive Competence of LEF1-Transduced ADMCs

The first passage of $1 \times 10^{5}$ ADMCs was placed into a 6-well culture dish. The following day, $2 \mu \mathrm{g}$ of CMV promoter-driven human LEF1 mammalian expression vector (a gift from Dr. Marian Waterman, University of California, Irvine, Calif., USA) in $100 \mu \mathrm{l}$ of serum-free DMEM was transfected into ADMCs with $6 \mu \mathrm{l}$ of FuGENE HD transfection reagent (Roche Applied Science) following the manufacturer's instruction. The transfection efficiency was determined by measuring the relative expression levels of LEF1 in the ADMCs 24 and $48 \mathrm{~h}$ after transfection, respectively, by qPCR. Forty-eight hours after transfection, $1 \times 10^{5}$ ES-ECs were placed and cultured on the top of ADMCs. Co-cultured cells were grown in KGM2 with or without $50 \mu \mathrm{g} / \mathrm{ml}$ vitamin $\mathrm{C}$ (VitC) and $10 \mathrm{nM}$ sonic hedgehog $(\mathrm{SHH})$ recombinant protein (Abcam, Cambridge, Mass., USA) for 3 days. Total RNA was purified using the RNeasy mini kit (Qiagen), and cDNA was synthesized from $2 \mu \mathrm{g}$ of total RNA per sample. Amelogenin expression levels in the cocultured cells were determined by qPCR.

\section{Results}

\section{Induction of an Epithelial Phenotype from $h E S C s$}

After culture with $1 \mu \mathrm{M}$ retinoid acid and $12.5 \mathrm{ng} / \mathrm{ml}$ BMP4 for 7 days, hESCs on Matrigel adopted a cobblestone-like epithelial morphology. As reported previously [Zheng et al., 2013], expression levels of the EC marker
Table 1. Sequences of primers used to characterize the expression levels of transcription factors in FDMCs and ADMCs

\begin{tabular}{llll}
\hline & Forward primer & Reverse primer & $\begin{array}{l}\text { Amplicon } \\
\text { size }\end{array}$ \\
\hline MSX1 & tcctcaagctgccagaagat & tctccagctctgcctcttgt & $342 \mathrm{bp}$ \\
MSX2 & acacaagaccaatcggaagc & gcagccattttcagcttttc & $222 \mathrm{bp}$ \\
DLX1 & ggaggaactctgttgcttcg & gcttgttctcgcctgttttc & $113 \mathrm{bp}$ \\
DLX2 & ttcggatagtgaacgggaag & gaagcacaaggtggagaagc & $271 \mathrm{bp}$ \\
DLX5 & ccaaccagccagagaaagaa & gcaaggcgaggtactgagtc & $150 \mathrm{bp}$ \\
GLI1 & ccaggaatttgactcccaagag & cagcatgtactgggctttgaa & $136 \mathrm{bp}$ \\
GLI2 & catggagcactacctccgttc & cgagggtcatctggtggtaat & $173 \mathrm{bp}$ \\
GLI3 & gaagtgctccactcgaacga & gtggctgcatagtgattgcg & $125 \mathrm{bp}$ \\
LHX6 & acttcagccgattcgggac & atggtgtcgtagtggatgcg & $196 \mathrm{bp}$ \\
LHX8 & gaggagttgcttggtggaa & tgcttgcataacctgaagctg & $204 \mathrm{bp}$ \\
LEF1 & aacatggtggaaaacgaagc & gggttggcagtgattgtctt & $201 \mathrm{bp}$ \\
RUNX2 & cagaccagcagcactccata & cagcgtcaacaccatcattc & $178 \mathrm{bp}$ \\
PAX9 & acagtgctgctccttctggt & ctttcaaggcagaagggttg & $277 \mathrm{bp}$ \\
PRX1 & gcccaattataggcccgattc & ggcaagaagtcggaggcatc & $247 \mathrm{bp}$ \\
PRX2 & cgtgggctcttttaggaagca & cctgacggaagcatccttcac & $116 \mathrm{bp}$ \\
TBX1 & acgacaacggccacattattc & cctcggcatatttctcgctatct & $102 \mathrm{bp}$ \\
GAPDH & accacagtccatgccatcac & tccaccacctgttgctgta & $452 \mathrm{bp}$ \\
\hline
\end{tabular}

CK14 were upregulated to an average of 44-fold in ESECs compared to noninduced hESCs. Addition of exogenous factors in the culture including $\mathrm{LiCl}$, recombinant human amelogenin protein, human amelotin protein or human fetal ameloblast lineage cell conditioned media failed to promote ES-ECs to express amelogenin indicated by qPCR analysis (data not shown).

\section{FDMCs, but Not ADMCs, Induced ES-ECs to Form Ameloblast Lineage Cells}

Co-cultured ES-ECs and ADMCs formed amorphous scattered aggregates, which increased in size with longer incubation times (fig. 1b). Hematoxylin and eosin staining showed that ES-ECs co-cultured with ADMCs formed large cell nests with no lumen (fig. 1d). These cell nests consisted of either cuboidal or polygonal ECs with low nuclear-to-cytoplasmic ratios. No extracellular protein was observed around cells under the microscope.

In contrast, when ES-ECs were co-cultured with FDMCs, cells lined up evenly in cultureware (fig. 1c) and reorganized to form acinus-like or structures (fig. 1e), or structures resembling the developing tooth organs (fig. 1f, g) or structures resembling the developing enamel occasionally (fig. 1g). ES-ECs appeared polarized and formed acinar structures comprising a sheet of ECs surrounding a hollow lumen (fig. 1e). Approximately $20 \%$ of the ECs reorganized to form a sheet to encase the under- 

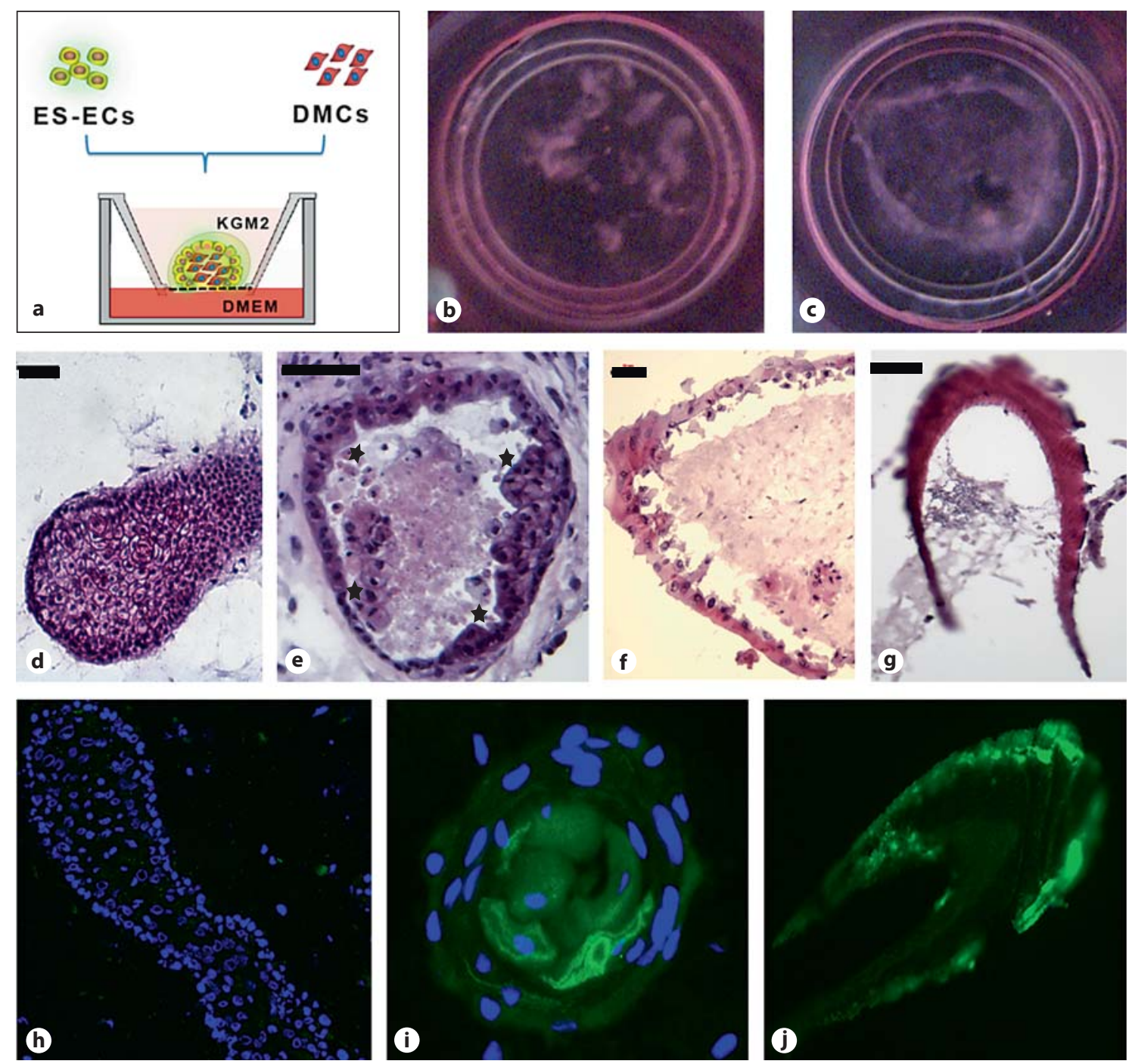

Fig. 1. ES-ECs adopted an ameloblast lineage phenotype when cocultured with FDMCs. a To facilitate cell compartmentalization for multicellular assembly and reciprocal signaling crosstalk, we cocultured ES-ECs and dental mesenchymal cells (DMCs) either from adult pulp or human fetal tooth organs in a 3-dimensional Matrigel drop system. First, DMCs were mixed with Matrigel and dropped on top of the Transwell membrane. Second, ES-ECs were mixed with Matrigel and then overlaid on the surface of DMCs/ Matrigel drop. For the first 2 weeks, KGM2 with $0.05 \mathrm{mM} \mathrm{CaCl}_{2}$ was added to the top of the Transwell membrane, and DMEM was added to the lower chamber. From weeks 3 to $8,1 \mathrm{mM} \mathrm{CaCl}_{2}$ was supplemented to KGM2 to induce EC differentiation, and ascorbic acid, $\beta$-glycerophosphate and dexamethasone were supplemented to DMEM to induce DMC differentiation. b Following ES-ECs coculture with ADMCs, cells were unevenly scattered on the Transwell. c Following ES-ECs co-culture with FDMCs, cells distributed more evenly on the Transwell. d H\&E staining of the cryosections showed that similar to co-culture with ADMCs, ES-ECs formed large and solid cellular aggregates. Cells did not polarize and no acinus-like structure could be found. There were two types of cells composed of aggregates: cubic or short columnar peripheral cells and cytoplasm-rich polygonal inner cells. No extracellular secretion or deposition could be observed. e Following co-culture with FDMCs, ES-ECs polarized. About $80 \%$ of cellular structures were acinus structures with ECs surrounding the lumen (indicated by black stars) in which extracellular matrix was visualized. f Following ES-ECs co-culture with FDMCs, about $20 \%$ of structures resembled epithelial sheets, which covered the underlying mesenchymal cells, forming a bud-like structure. g Occasionally, the developing enamel-like structures could be found in the ES-EC and FDMC co-culture complexes. $\mathbf{h}$ There was no positive amelogenin immunostaining signal in the solid epithelial aggregates as ES-ECs cocultured with ADMCs. i While co-culture with FDMCs, ES-ECs formed acinus structures staining positive for amelogenin. $\mathbf{j}$ Enamel-like structure stained positively for amelogenin. Scale bars: $50 \mu \mathrm{m}$.

(For Fig. 1k see next page.)

Inductive Ability of Human Developing and Differentiated Dental Mesenchyme
Cells Tissues Organs 2013;198:99-110 DOI: $10.1159 / 000353116$ 
Fig. 1. ES-ECs adopted an ameloblast lineage phenotype when co-cultured with FDMCs. k qPCR analysis showed that there was no detectable amelogenin expression in ES-ECs grown in Matrigel alone. Amelogenin expression levels of ESEC/FDMC complexes were approximately 15 -fold greater than those in FDMCs, which had baseline expression levels of amelogenin. The expression levels of amelogenin in ES-ECs/ADMCs were $12.5 \%$ of the levels of FDMCs. Scale bars: $50 \mu \mathrm{m}$.
Cultured cells

Amelogenin: relative expression levels vs. FDMCs (mean $\pm \mathrm{SD}$ )

\begin{tabular}{lr}
\hline ES-ECs & undetected \\
ADMCs & $0.125 \pm 0.029$ \\
FDMCs & $1 \pm 0.076$ \\
ADMCs/ES-ECs & $0.125 \pm 0.046$ \\
FDMCs/ES-ECs & $14.75 \pm 1.10$
\end{tabular}

Fig. 2. ES-ECs formed tooth primordiallike structures and stained positive for amelogenin after cotransplantation with FDMCs in the SCID mouse kidney capsules. Implanted ADMCs (a) or FDMCs (b) randomly scattered in the Matrigel scaffold and failed to form any specialized structure. c Implanted ES-ECs formed spherical epithelial nest structures. d Following cotransplantation with ADMCs, ES-ECs formed tightly compacted aggregates consisting of cells with signs of keratinization. e Hair-like structures (indicated by the white arrows) were occasionally detected in the transplants with ES-ECs and ADMCs. $f$ Cotransplanted ES-ECs/FDMCs formed tooth primordial-like structures. Cells were polarized (dotted line). g Epithelial sheets stained positive for amelogenin.
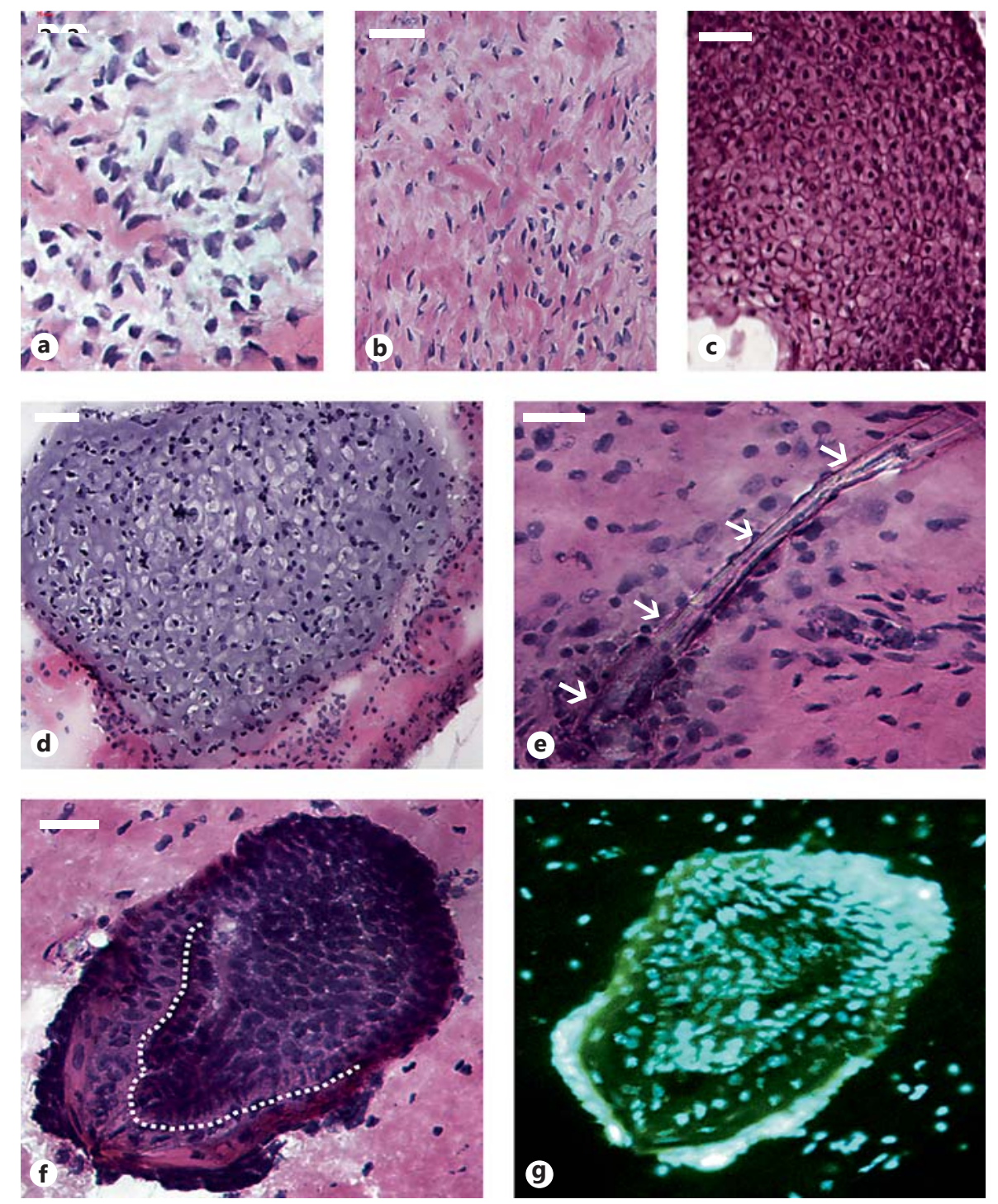
Fig. 3. Conventional PCR analysis revealed the transcription factors that were significantly upregulated in the human FDMCs compared to ADMCs. a The PCR amplification products of target genes were visualized on agarose gel. Template total RNA was extracted from DMCs of 3 human fetuses and 4 adult individuals. b Densitometric analysis on the electrophoretic bands showed that 6 transcription factors were significantly upregulated in the FDMCs compared to ADMCs $(* \mathrm{p}<0.05$; Student's t test).

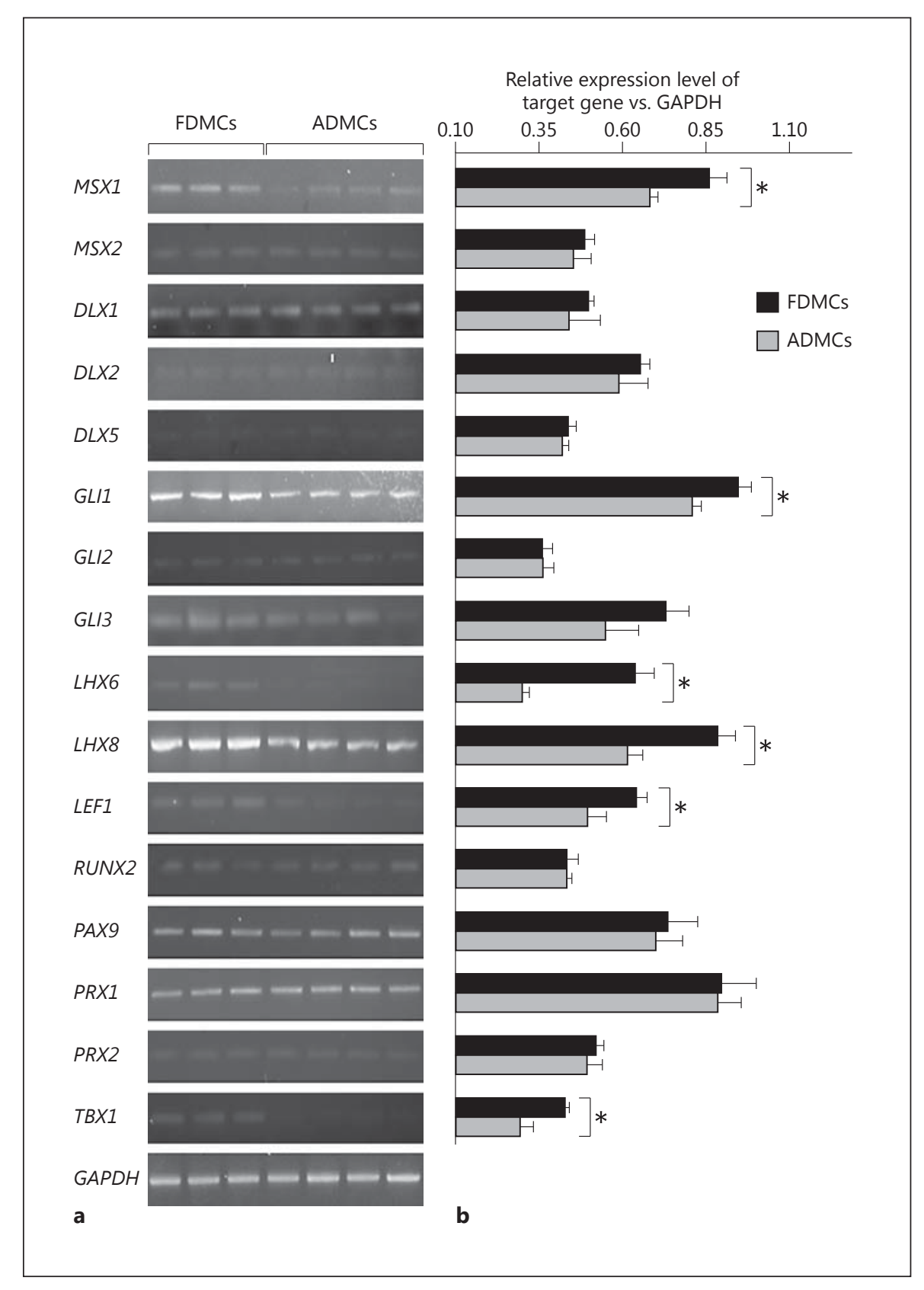

lying mesenchymal tissues, similar to a developing tooth organ structure (fig. 1f).

Amelogenin immunostaining was negative in the structures formed by co-cultured ADMCs/ES-ECs (fig. 1h), whereas epithelial sheets from FDMC/ES-EC co-culture stained positive for amelogenin (fig. 1i, j). The center of acinus-like structures was amelogenin immunopositive (fig. 1i). qPCR showed that the co-cultured FDMCs/ES-ECs expressed the highest level of amelo- genin compared to that of all other conditions. Amelogenin expression levels in co-cultured FDMCs/ES-ECs increased approximately 15 -fold compared to that of FDMCs, which expressed low baseline levels of amelogenin (fig. 1k). Amelogenin was barely detected in ADMCs or in co-cultured ADMCs/ES-ECs.

In the kidney capsule transplants, ADMCs or FDMCs alone randomly scattered as fibroblast-like cells (fig. 2a, b). Epithelial nests were detected when ES-ECs were trans- 


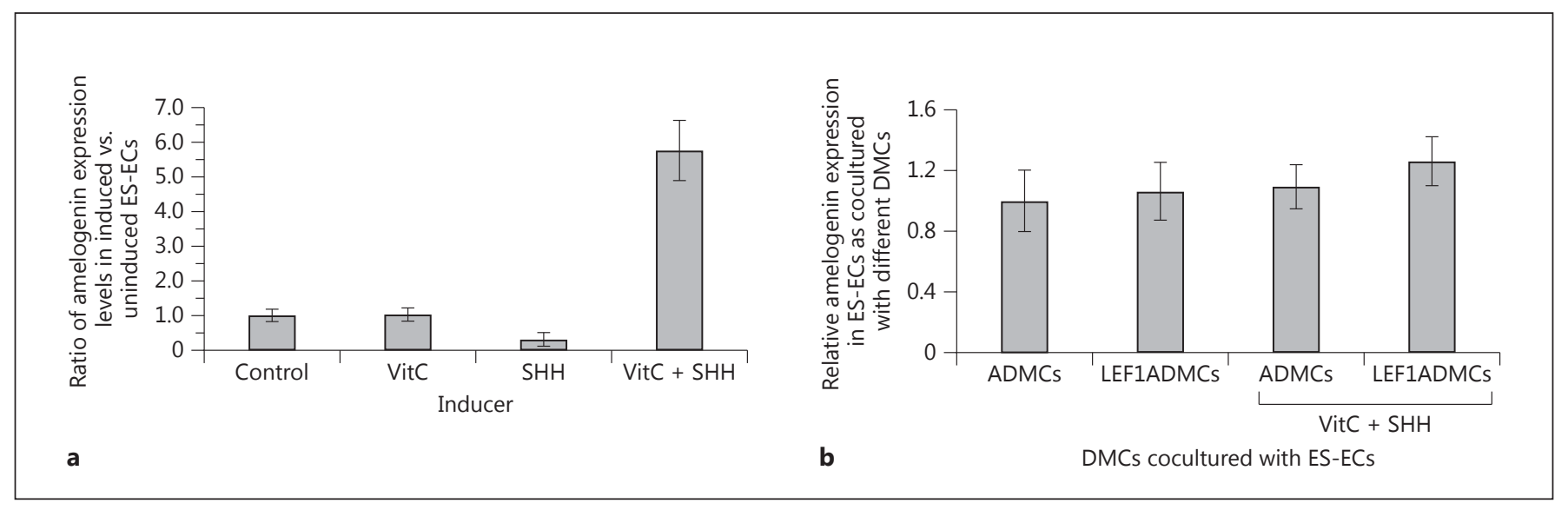

Fig. 4. LEF1-transduced ADMCs (LEF1ADMCs) could not induce co-cultured ES-ECs to express amelogenin. a VitC and SHH recombinant protein could synergically upregulate amelogenin expression in the ES-ECs, though VitC or $\mathrm{SHH}$ alone did not have such an effect. However, this effect was suppressed as ES-ECs were cocultured with either ADMCs or LEF1ADMCs (b), since amelogenin expression was not significantly different following co-culture of ES-ECs with either ADMCs or LEF1ADMCs. planted alone (fig. 2c). ES-ECs cotransplanted with ADMCs formed solid cell aggregates. In these aggregates, ECs had a low nuclear-to-cytoplasmic ratio and more transparent cytoplasm, adopting the morphology of keratinized squamous ECs (fig. 2d). Occasionally, hair-like structures (indicated by white arrows) were detected in the tissues derived from ES-ECs cotransplanted with ADMCs (fig. 2e).

Cellular structures resembling early stages of budshaped tooth primodia were observed in the tissues derived from FDMC/ES-EC transplantation (fig. 2f, g). Immunofluorescent staining showed epithelium in the FDMC/ES-EC transplant started to express amelogenin (indicated by the white dotted line; fig. 2f).

Genes Encoding Transcription Factors MSX1, GLI1, LHX6, LHX8, LEF1 and TBX1 Were Upregulated in FDMCs Compared to ADMCs

Densitometry measurement of electrophoresis bands of conventional PCR amplification products for a panel of 16 transcription factors known to be upregulated in mouse embryonic dental mesenchyme [Thesleff and Tummers, 2008] demonstrated that 6 factors, including MSX1, GLI1, LHX6, LHX8, LEF1 and TBX1, were significantly upregulated in FDMCs compared to ADMCs (fig. 3).

To further investigate the correlation of LEF1 temporal upregulation in dental mesenchyme with its odontogenic potential, we compared Lefl expression in lasermicrodissected and captured dental mesenchyme from embryonic day (E)14.5 and postnatal day (P) 4 mouse molars. E14.5 mouse dental mesenchyme had a 33-fold in- crease in the expression of Lef1 compared to P4 cells. Similarly, FDMCs had a 35-fold greater LEF1 expression compared to ADMCs based on real-time PCR analysis (see online suppl. fig. 1; for all online suppl. material, see www.karger.com/doi/10.1159/000353116).

\section{LEF1 Transfection Failed to Enhance the Odontogenic Instructive Competence of ADMCs}

The results from our and other studies suggested that LEF1 was a stage-specific transcription factor, and as such was a candidate to induce odontogenic competence of ADMCs. Transfection of ADMCs with the LEF1 expression vector resulted in upregulation of $L E F 1$ : 830 -fold at $24 \mathrm{~h}$ and 940 -fold at $48 \mathrm{~h}$ after transfection on average. However, we could not detect amelogenin expression in either co-cultured ES-ECs/ADMCs or ES-EC/LEF1transduced ADMCs (LEF1ADMCs; fig. 4).

We found that supplementation of KGM2 with both $\mathrm{VitC}$ and recombinant SHH protein could induce ES-ECs to express amelogenin (fig. 4a). However, when VitC and SHH were added to the co-cultured ES-ECs/ADMCs and ES-ECs/LEF1ADMCs, amelogenin expression was not altered (fig. $4 \mathrm{~b}$ ).

\section{Discussion}

A number of previous studies have shown that starting from the bud stage, the odontogenic instructive competence resides in dental mesenchyme [Kollar and Baird, 
1970; Yoshikawa and Kollar, 1981]. Mesenchymal cells isolated from bud and after bud stage mouse tooth organs can induce the differentiation of both dental ECs and nondental ECs to form tooth structures [Young et al., 2002; Duailibi et al., 2004; Ohazama et al., 2004; Hu et al., 2006; Yu et al., 2007]; however, this odontogenic competence is lost in postnatal mouse mesenchymal cells [Kollar and Baird, 1970; Yoshikawa and Kollar, 1981]. Therefore, elucidation of the key molecular mechanisms responsible for the odontogenic competence of developing dental mesenchyme may allow us to reprogram DMCs available from fully formed teeth.

Our studies are the first to investigate the relative odontogenic instructive competence of human dental mesenchyme from developing tooth organs and from fully differentiated adult dental pulp tissues. They are also the first to explore the potential of ECs derived from hESCs to be used as an EC source for regeneration of ameloblast lineage cells. To form the enamel matrix, ameloblasts must secrete enamel matrix proteins, and in particular amelogenin. Therefore, we used amelogenin expression as a marker of ameloblast differentiation.

We found no effect on ES-EC differentiation when we added extracellular enamel matrix proteins, including full length recombinant amelogenin and amelotin, which is upregulated during the maturation stage, to the culture media. Likewise, addition of $\mathrm{LiCl}$, a Wnt signaling activator [Hedgepeth et al., 1997], or conditioned media collected from cultured primary human fetal ameloblast lineage cells did not induce ES-ECs to express amelogenin. Ning et al. [2010] found that ameloblast serum-free conditioned media could instruct mouse embryonic stem cells to commit into amelogenin-secreting cells. The lack of similar results using hESCs may imply that mouse embryonic stem cells possess different plasticity from the hESCs.

We explored the properties of developing dental mesenchyme isolated from human fetal tooth organs compared to dental pulp cells derived from fully formed third molars in inducing ES-EC differentiation. Similar to classic mouse tooth tissue recombination experiments [Kollar and Baird, 1970; Richman and Kollar, 1986; Mina and Kollar, 1987; Young et al., 2002; Duailibi et al., 2004; Nakao et al., 2007; Ikeda et al., 2009] which show the inductive capacity of the developing dental mesenchyme to differentiate either dental ECs or even nondental ECs to ameloblasts, we found that human developing mouse dental mesenchyme could also induce ECs derived from hESCs to differentiate into ameloblasts. Evidence of cell reorganization to form an ameloblast layer surrounding

Inductive Ability of Human Developing and Differentiated Dental Mesenchyme mesenchymal cells was found in co-culture. Ex vivo coculture of FDMCs and ES-ECs in SCID mouse kidney capsules showed some cell reorganization similar to a tooth bud phenotype, while other cells formed circular structures.

These results using human dental mesenchyme showed for the first time that human developing dental mesenchyme has properties consistent with observations from many classical recombination studies, in which mouse developing dental mesenchyme can induce epithelial differentiation. In mouse studies, this capacity was found to start from the bud stage, and decline through the cap and bell stage [Kollar and Baird, 1970; Yoshikawa and Kollar, 1981; Nakao et al., 2007; Takahashi et al., 2010]. The human fetal dental mesenchyme used for our recombination experiments was harvested from a collection of tooth organs ranging from early to late bell stage. Therefore, we would expect DMCs with different induction potentials in our co-cultures. Indeed, in approximately $20 \%$ of the cellular structures, the morphology is similar to that of developing tooth primordia, and the remaining structures were acinar structures, similar to what we have seen in previous in vivo studies when human adult pulp stem cells were recombined with human fetal ameloblast lineage cells [He et al., 2010]. Occasionally, we found hair-like structures formed in the tissues derived from ADMCs and ES-ECs cotransplantation. Both our results and other studies point to the potential use of adult dental mesenchymal stem cells in regenerating dermal papillae and hair follicles [Kollar and Baird, 1970; Thesleff et al., 1995b].

The achievement of inducing ameloblast differentiation by human developing dental mesenchyme enables us to explore the possibility of restoring this capacity in more accessible human adult dental pulp stem cells. We compared the relative expression levels of 16 transcription factors that have previously been identified to be associated with odontogenic competence of embryonic mouse dental mesenchyme [Thesleff and Tummers, 2008] in FDMCs versus ADMCs. We identified that LEF1, MSX1, GLI1, LHX6, LHX8 and TBX1 were significantly upregulated in FDMCs compared to ADMCs. LHX6 had the most profound upregulation in FDMCs versus ADMCs. Mice with deletion in the LHX6 gene alone have normal tooth development; however, LHX6/LHX7-deficient mouse embryos lack molar teeth [Denaxa et al., 2009].

LEF1 is a transcription factor that mediates canonical Wnt signaling by interacting with $\beta$-catenin [Eastman and Grosschedl, 1999]. In mouse, Lef1 mutants lack hair, 
whiskers, mammary glands and teeth, which are arrested at the bud stage [van Genderen et al., 1994]. Previous studies showed a 37.4-fold decrease in Lef1 expression in mouse E18 (late bell stage) dental mesenchyme compared to mouse E16 (early bell stage) dental mesenchyme [Sasaki et al., 2010], similar to the 35-fold decrease in LEF1 expression that we found in ADMCs compared to FDMCs. Therefore, we investigated whether upregulation of LEF1 could enhance the ability of ADMCs to induce the recombined ECs to assume an ameloblast phenotype. Though we could successfully upregulate $L E F 1$ in ADMCs, overexpression of LEF1 alone did not enhance the ability of ADMCs to induce the ameloblastic commitment of co-cultured ES-ECs. Interestingly, although we could increase amelogenin expression by directly adding VitC and SHH to ES-ECs [Bronckers, 1983; Takahashi et al., 2007; Seidel et al., 2010], amelogenin was again downregulated when ES-ECs grown with VitC and SHH were subsequently co-cultured with LEF1-transduced ADMCs.

We did not detect any significant difference between FDMCs and ADMCs in the expression levels of other transcription factors, including $P A X 9, P R X 1$ and $P R X 2$. These results were unexpected, as previous loss-of-function genetic mouse model studies have demonstrated the indispensable roles of these molecules [Satokata and Maas, 1994; Peters et al., 1998; D’Souza et al., 1999; Shibaguchi et al., 2003; Mitchell et al., 2006; Mitsiadis et al., 2008; Denaxa et al., 2009] in regulating early tooth development. Expression of these genes may peak during bud stage and start to decline beyond cap stage, which may explain why we saw no change in their expression levels between FDMCs (mostly bell stage) and ADMCs.
The reports of directly transdifferentiating somatic cells to functional cardiomyocytes and neurons with several cell type-specific transcription factors [Ieda et al., 2010; Vierbuchen et al., 2010] suggest the feasibility of reprogramming somatic adult dental mesenchyme for tooth bioengineering purposes. These strategies would facilitate the use of tissues from the same individual for regeneration of tooth tissue specifically, sidestepping issues related to ethics and tissue rejection.

Here, we have shown for the first time that ECs derived from hESCs can be induced to form polarized amelogenin-generating cells by co-culturing with human developing dental mesenchyme. Although odontogenic human fetal and mouse bud stage dental mesenchyme expressed relative higher levels of $L E F 1$, overexpressing LEF1 alone in the human ADMCs was not sufficient to reprogram adult pulp cells to gain their odontogenic inductive ability. Future studies will need to optimize the expression levels and combination of potential transcription factors sufficient to transdifferentiate these ADMCs.

Deciphering the repertoire of transcription factors associated with the odontogenic potential of developing human dental mesenchyme will help pave the way for the regeneration of the odontogenic potential in the accessible adult dental mesenchyme.

\section{Acknowledgments}

This study was supported by NIH/NIDCR grants R03 DE019507-02 to Yan Zhang, R21 DE018633 to Pamela K. DenBesten and a New Faculty II Award from the California Institute of Regenerative Medicine to Ophir Klein.

\section{References}

Bei, M., R. Maas (1998) FGFs and BMP4 induce both Msx1-independent and Msx1-dependent signaling pathways in early tooth development. Development 125: 4325-4333.

Beniash, E., J.P. Simmer, H.C. Margolis (2005) The effect of recombinant mouse amelogenins on the formation and organization of hydroxyapatite crystals in vitro. J Struct Biol 149: $182-190$

Bronckers, A.L. (1983) A histological and biochemical study of the effect of vitamin C-deficiency on induction of amelogenesis in hamster molars in vitro. Arch Oral Biol 28: 681-692.

\begin{abstract}
Cai, J., N. Mutoh, J.O. Shin, N. Tani-Ishii, H. Ohshima, S.W. Cho, H.S. Jung (2011) Wnt5a plays a crucial role in determining tooth size during murine tooth development. Cell Tissue Res 345: 367-377.

Clark, A.T., R.T. Rodriguez, M.S. Bodnar, M.J. Abeyta, M.I. Cedars, P.J. Turek, M.T. Firpo, R.A. Reijo Pera (2004) Human STELLAR, NANOG, and GDF3 genes are expressed in pluripotent cells and map to chromosome 12 p13, a hotspot for teratocarcinoma. Stem Cells 22: 169-179.

Cummings, E.G., P. Bringas, Jr., M.S. Grodin, H.C. Slavkin (1981) Epithelial-directed mesenchyme differentiation in vitro model of murine odontoblast differentiation mediated by quail epithelia. Differentiation 20: 1-9. M. Owen, G. Karsenty, I. Thesleff (199) M. Owen, G. Karsenty, I. Thesleff (1999) Cbfal is required for epithelial-mesenchyma mice. Development 126: 2911-2920. M., P.T. Sharpe, V. Pachnis (2009) The LIM homeodomain transcription factors Lhx6 and Lhx7 are key regulators of mammalian dentition. Dev Biol 333: 324-336.

uailibi, M.T., S.E. Duailibi, C.S. Young, J.D. Bartlett, J.P. Vacanti, P.C. Yelick (2004) Bioengineered teeth from cultured rat tooth bud cells. J Dent Res 83: 523-528.

Eastman, Q., R. Grosschedl (1999) Regulation of LEF-1/TCF transcription factors by Wnt and other signals. Curr Opin Cell Biol 11: 233240 .
\end{abstract}


Estrela, C., A.H. Alencar, G.T. Kitten, E.F. Vencio, E. Gava (2011) Mesenchymal stem cells in the dental tissues: perspectives for tissue regeneration. Braz Dent J 22: 91-98.

Fincham, A.G., J. Moradian-Oldak, J.P. Simmer, P. Sarte, E.C. Lau, T. Diekwisch, H.C. Slavkin (1994) Self-assembly of a recombinant amelogenin protein generates supramolecular structures. J Struct Biol 112: 103-109.

Green, H., K. Easley, S. Iuchi (2003) Marker succession during the development of keratinocytes from cultured human embryonic stem cells. Proc Natl Acad Sci USA 100: 15625-15630.

Gronthos, S., J. Brahim, W. Li, L.W. Fisher, N. Cherman, A. Boyde, P. DenBesten, P.G. Robey, S. Shi (2002) Stem cell properties of human dental pulp stem cells. J Dent Res 81: 531-535.

Gronthos, S., M. Mankani, J. Brahim, P.G. Robey, S. Shi (2000) Postnatal human dental pulp stem cells (DPSCs) in vitro and in vivo. Proc Natl Acad Sci USA 97: 13625-13630.

-Hardcastle, Z., R. Mo, C.C. Hui, P.T. Sharpe (1998) The Shh signalling pathway in tooth development: defects in Gli2 and Gli3 mutants. Development 125: 2803-2811.

He, P., Y. Zhang, S.O. Kim, R.J. Radlanski, K. Butcher, R.A. Schneider, P.K. DenBesten (2010) Ameloblast differentiation in the human developing tooth: effects of extracellular matrices. Matrix Biol 29: 411-419.

Hedgepeth, C.M., L.J. Conrad, J. Zhang, H.C. Huang, V.M. Lee, P.S. Klein (1997) Activation of the Wnt signaling pathway: a molecular mechanism for lithium action. Dev Biol 185: 82-91.

Hu, B., A. Nadiri, S. Kuchler-Bopp, F. PerrinSchmitt, H. Peters, H. Lesot (2006) Tissue engineering of tooth crown, root, and periodontium. Tissue Eng 12: 2069-2075.

Ieda, M., J.D. Fu, P. Delgado-Olguin, V. Vedantham, Y. Hayashi, B.G. Bruneau, D. Srivastava (2010) Direct reprogramming of fibroblasts into functional cardiomyocytes by defined factors. Cell 142: 375-386.

-Ikeda, E., R. Morita, K. Nakao, K. Ishida, T. Nakamura, T. Takano-Yamamoto, M. Ogawa, M. Mizuno, S. Kasugai, T. Tsuji (2009) Fully functional bioengineered tooth replacement as an organ replacement therapy. Proc Natl Acad Sci USA 106: 13475-13480.

Klimanskaya, I., J. Hipp, K.A. Rezai, M. West, A. Atala, R. Lanza (2004) Derivation and comparative assessment of retinal pigment epithelium from human embryonic stem cells using transcriptomics. Cloning Stem Cells 6: 217-245.

Kollar, E.J., G.R. Baird (1970) Tissue interactions in embryonic mouse tooth germs. II. The inductive role of the dental papilla. J Embryol Exp Morphol 24: 173-186.

Metallo, C.M., L. Ji, J.J. de Pablo, S.P. Palecek (2008) Retinoic acid and bone morphogenetic protein signaling synergize to efficiently direct epithelial differentiation of human embryonic stem cells. Stem Cells 26: 372-380.
Mina, M., E.J. Kollar (1987) The induction of odontogenesis in non-dental mesenchyme combined with early murine mandibular arch epithelium. Arch Oral Biol 32: 123-127.

Mitchell, J.M., D.M. Hicklin, P.M. Doughty, J.H. Hicklin, J.W. Dickert, Jr., S.M. Tolbert, R. Peterkova, M.J. Kern (2006) The Prx1 homeobox gene is critical for molar tooth morphogenesis. J Dent Res 85: 888-893.

Mitsiadis, T.A., A.S. Tucker, C. De Bari, M.T. Cobourne, D.P. Rice (2008) A regulatory relationship between Tbx1 and FGF signaling during tooth morphogenesis and ameloblast lineage determination. Dev Biol 320: 39-48.

-Miura, M., S. Gronthos, M. Zhao, B. Lu, L.W. Fisher, P.G. Robey, S. Shi (2003) SHED: stem cells from human exfoliated deciduous teeth. Proc Natl Acad Sci USA 100: 5807-5812.

Moradian-Oldak, J., J. Tan, A.G. Fincham (1998) Interaction of amelogenin with hydroxyapatite crystals: an adherence effect through amelogenin molecular self-association. Biopolymers 46: 225-238.

Nakao, K., R. Morita, Y. Saji, K. Ishida, Y. Tomita, M. Ogawa, M. Saitoh, Y. Tomooka, T. Tsuji (2007) The development of a bioengineered organ germ method. Nat Methods 4: 227-230.

Ning, F., Y. Guo, J. Tang, J. Zhou, H. Zhang, W. Lu, Y. Gao, L. Wang, D. Pei, Y. Duan, Y. Jin (2010) Differentiation of mouse embryonic stem cells into dental epithelial-like cells induced by ameloblasts serum-free conditioned medium. Biochem Biophys Res Commun 394: 342-347.

-Ohazama, A., S.A. Modino, I. Miletich, P.T. Sharpe (2004) Stem-cell-based tissue engineering of murine teeth. J Dent Res 83: 518522.

Peters, H., A. Neubuser, K. Kratochwil, R. Balling (1998) Pax9-deficient mice lack pharyngeal pouch derivatives and teeth and exhibit craniofacial and limb abnormalities. Genes Dev 12: 2735-2747.

Richman, J.M., E.J. Kollar (1986) Tooth induction and temporal patterning in palatal epithelium of fetal mice. Am J Anat 175: 493-505.

Robinson, C., S.J. Brookes, R.C. Shore, J. Kirkham (1998) The developing enamel matrix: nature and function. Eur J Oral Sci 106(suppl 1): 282291.

Ruch, J.V., H. Lesot, V. Karcher-Djuricic, J.M. Meyer, M. Mark (1983) Epithelial-mesenchymal interactions in tooth germs: mechanisms of differentiation. J Biol Buccale 11: 173-193.

Sasaki, H., T. Muramatsu, H.J. Kwon, H. Yamamoto, S. Hashimoto, H.S. Jung, M. Shimono (2010) Down-regulated genes in mouse dental papillae and pulp. J Dent Res 89: 679-683.

Satokata, I., R. Maas (1994) Msx1 deficient mice exhibit cleft palate and abnormalities of craniofacial and tooth development. Nat Genet 6: 348-356.
Seidel, K., C.P. Ahn, D. Lyons, A. Nee, K. Ting, I. Brownell, T. Cao, R.A. Carano, T. Curran, M. Schober, et al. (2010) Hedgehog signaling regulates the generation of ameloblast progenitors in the continuously growing mouse incisor. Development 137: 3753-3761.

-Shibaguchi, T., J. Kato, M. Abe, Y. Tamamura, M.J. Tabata, J.G. Liu, M. Iwamoto, S. Wakisaka, A. Wanaka, K. Kurisu (2003) Expression and role of Lhx8 in murine tooth development. Arch Histol Cytol 66: 95-108.

Sonoyama, W., Y. Liu, T. Yamaza, R.S. Tuan, S. Wang, S. Shi, G.T. Huang (2008) Characterization of the apical papilla and its residing stem cells from human immature permanent teeth: a pilot study. J Endod 34: 166-171.

Takahashi, C., H. Yoshida, A. Komine, K. Nakao, T. Tsuji, Y. Tomooka (2010) Newly established cell lines from mouse oral epithelium regenerate teeth when combined with dental mesenchyme. In Vitro Cell Dev Biol Anim 46: 457-468.

-Takahashi, S., N. Kawashima, K. Sakamoto, A. Nakata, T. Kameda, T. Sugiyama, K. Katsube, H. Suda (2007) Differentiation of an ameloblast-lineage cell line (ALC) is induced by Sonic hedgehog signaling. Biochem Biophys Res Commun 353: 405-411.

Thesleff, I., K. Hurmerinta (1981) Tissue interactions in tooth development. Differentiation 18: 75-88.

Thesleff, I., M. Mikkola (2002) The role of growth factors in tooth development. Int Rev Cytol 217: 93-135.

Thesleff, I., P. Sharpe (1997) Signalling networks regulating dental development. Mech Dev 67: 111-123.

Thesleff, I., M. Tummers, M. (2008) Tooth organogenesis and regeneration.

Thesleff, I., A. Vaahtokari, P. Kettunen, T. Aberg (1995a) Epithelial-mesenchymal signaling during tooth development. Connect Tissue Res 32: 9-15.

Thesleff, I., A. Vaahtokari, A.M. Partanen (1995b) Regulation of organogenesis. Common molecular mechanisms regulating the development of teeth and other organs. Int J Dev Biol 39: 35-50.

Thomas, J.T., M.W. Kilpatrick, K. Lin, L. Erlacher, P. Lembessis, T. Costa, P. Tsipouras, F.P. Luyten (1997) Disruption of human limb morphogenesis by a dominant negative mutation in CDMP1. Nat Genet 17: 58-64.

Thomsen, R., C.A. Solvsten, T.E. Linnet, J. Blechingberg, A.L. Nielsen (2010) Analysis of qPCR data by converting exponentially related Ct values into linearly related $\mathrm{X} 0$ values. J Bioinform Comput Biol 8: 885-900.

Vaahtokari, A., T. Aberg, I. Thesleff (1996) Apoptosis in the developing tooth: association with an embryonic signaling center and suppression by EGF and FGF-4. Development 122: 121-129.
Inductive Ability of Human Developing and Differentiated Dental Mesenchyme
Cells Tissues Organs 2013;198:99-110 DOI: $10.1159 / 000353116$ 
van Genderen, C., R.M. Okamura, I. Farinas, R.G. Quo, T.G. Parslow, L. Bruhn, R. Grosschedl (1994) Development of several organs that require inductive epithelial-mesenchymal interactions is impaired in LEF-1-deficient mice. Genes Dev 8: 2691-2703.

-Vierbuchen, T., A. Ostermeier, Z.P. Pang, Y. Kokubu, T.C. Sudhof, M. Wernig (2010) Direct conversion of fibroblasts to functional neurons by defined factors. Nature 463: 10351041.
Yan, Q., Y. Zhang, W. Li, P.K. DenBesten (2006) Differentiation of human ameloblast-lineage cells in vitro. Eur J Oral Sci 114(suppl 1): 154158, discussion 164-155, 380-151.

Yoshikawa, D.K., E.J. Kollar (1981) Recombination experiments on the odontogenic roles of mouse dental papilla and dental sac tissues in ocular grafts. Arch Oral Biol 26: 303-307.

Young, C.S., S. Terada, J.P. Vacanti, M. Honda, J.D. Bartlett, P.C. Yelick (2002) Tissue engineering of complex tooth structures on biodegradable polymer scaffolds. J Dent Res 81 : 695-700.

Yu, J., Y. Wang, Z. Deng, L. Tang, Y. Li, J. Shi, Y. Jin (2007) Odontogenic capability: bone marrow stromal stem cells versus dental pulp stem cells. Biol Cell 99: 465-474.
Zhang, Y., Q. Yan, W. Li, P.K. DenBesten (2006) Fluoride down-regulates the expression of matrix metalloproteinase- 20 in human fetal tooth ameloblast-lineage cells in vitro. Eur J Oral Sci 114(suppl 1): 105-110, discussion 127-109, 380.

Zheng, L.W., L. Linthicum, P.K. Denbesten, Y. Zhang (2013) The similarity between human embryonic stem cell-derived epithelial cells and ameloblast-lineage cells. Int J Oral Sci 5: $1-6$. 